\title{
A comprehensive model integrating UTAUT and ECM with espoused cultural values for investigating users' continuance intention of using mobile payment
}

\author{
Yuyang Zhao \\ NOVA Information Management School (NOVA IMS), \\ Universidade Nova de Lisboa, \\ Campus de Campolide, \\ 1070-312 Lisboa, Portugal \\ +86 15639937263 \\ d2015046@novaims.unl.pt
}

\author{
Fernando Bacao \\ NOVA Information Management School (NOVA IMS), \\ Universidade Nova de Lisboa, \\ Campus de Campolide, \\ 1070-312 Lisboa, Portugal \\ +351213828610 \\ bacao@novaims.unl.pt
}

\begin{abstract}
Mobile payment (M-payment), as an emerging financial transaction method has been widely adopted in various contexts. In order to investigate the significance factors and espoused cultural moderators impacting users' M-payment continuance usage intention in China, this study proposes a comprehensive model integrating Unified Theory of Acceptance and Use of Technology (UTAUT) and Expectancy Confirmation Model (ECM) with trust variable espoused by Hofstede's cultural value to investigate factors affecting users' continuance intention of using M-payment. In addition, based on the proposed model, researchers can more accurately explain user' behavior not only corresponding technological perceptions, but also mental expectations and espoused cultural values for various technology continuance acceptance under different cultural background.
\end{abstract}

\section{CCS Concepts}

- Computing methodologies $\rightarrow$ Modeling and simulation $\rightarrow$ Model development and analysis $\rightarrow$ Modeling methodologies

\section{Keywords}

Mobile payment; continuance intention; Unified Theory of Acceptance and Use of Technology (UTAUT); Expectancy Confirmation Model (ECM); espoused cultural values.

\section{INTRODUCTION}

Mobile payment (M-payment) as burgeoning payment method has dramatically increased in recent years. According to WorldPay report, M-payment accounted for $22 \%$ of global point of sale spend in 2019 and has been estimated will increase to $29.6 \%$ in 2023 [1]. Accordingly, smartphone users' consuming habit has significantly changed. Quick Response (QR) based M-payment drove nearly half (48\%) of point of sale payments in 2019 in

Permission to make digital or hard copies of all or part of this work for personal or classroom use is granted without fee provided that copies are not made or distributed for profit or commercial advantage and that copies bear this notice and the full citation on the first page. Copyrights for components of this work owned by others than ACM must be honored. Abstracting with credit is permitted. To copy otherwise, or republish, to post on servers or to redistribute to lists, requires prior specific permission and/or a fee. Request permissions from Permissions@acm.org.

ICBDT 2020, September 18-20, 2020, Qingdao, China

(C) 2020 Association for Computing Machinery.

ACM ISBN 978-1-4503-8785-9/20/09...

https://doi.org/10.1145/3422713.3422754
China [1]. Therefore, the factors determining users' continuance usage of M-payment are valuable for relevant stakeholders comprehensively understanding users' expectation and behavior. Previous studies have applied various adoption models (e.g. Technology Acceptance Model (TAM), Diffusion of Innovation Model (DOI), Unified Theory of Acceptance and Use of Technology (UTAUT), etc.) to explain users' intention of Mpayment adoption [2][3]. However, a limited number of researches have focused on users' continuance intention of using M-payment, especially under cultural moderators' effect.

Incorporating cultural value as both a predictor and a moderator as crucial information affecting consumer decision making by shaping perceptions and preferences of products, services and innovations on theorical and practical aspects of technology adoption [4][5][6]. Moreover, cultural values consist of following dimensions, collectivism/individualism, masculinity/femininity, power distance, uncertainty avoidance, and long-term orientation [4]. Specifically, according to the updated information provided by Hofstede Insights with 100-point scale, scores of China in power distance is 80, individualism-collectivism is 20, masculinity is 66, uncertainty avoidance is 30 , and Long-term orientation is 87 .

Furthermore, traditional adoption models (e.g. TAM and UTAUT) evaluate users' intention determined by technological perceptions with obvious limitation of influence from users' mental perception [7]. Meanwhile, Expectancy Confirmation Model (ECM) efficiently explains users' mental expectations by users' confirmation and satisfaction on their continuance intention of using technology [8]. Therefore, this study proposes a complementary model integrating UTAUT and ECM with cultural value to explain users' continuance intention of using M-payment. The paper is structured in sections as follows: literature review, development of hypotheses and proposed model; subsequently, future research; and conclusion.

\section{THEORICAL BACKGROUND}

\subsection{Continuance usage of mobile payment}

M-payment, as a contactless financial transaction method for paying goods, services, and bills by mobile device became a new business climate. The wide adoption of M-payment facilitates financial transactions anywhere, anytime and for anyone [2]. Comparing with the majority of previous studies generally focused on M-payment initial adoption [2][3][9][10], there are a limited number of studies concentrated on continuance usage intention of M-payment. This paper summarized prior studies 
related to continuance intention of using mobile technology in Table 1 with relevant theorical frameworks and variables. Specifically, it can be summarized that UTAUT as increasingly prime theorical model for exploring users' continuance intention of using mobile technology. Moreover, performance expectancy, social influence, trust and satisfaction are the most significant predictors. However, effect of cultural value been ignored by most of previous studies. Therefore, it is necessary to incorporate cultural value to explain users' continuance intention on $\mathrm{M}$ payment.

Table 1. Reviewing of previous literatures related to continuance intention on mobile technologies

\begin{tabular}{|c|c|c|}
\hline Studies & $\begin{array}{l}\text { Theorical } \\
\text { frameworks }\end{array}$ & Variables \\
\hline [11] & $\begin{array}{l}\text { IS success } \\
\text { model }\end{array}$ & $\begin{array}{l}\text { System quality, information } \\
\text { quality, service quality, trust, } \\
\text { flow and satisfaction }\end{array}$ \\
\hline [12] & $\begin{array}{l}\text { IS success } \\
\text { model }\end{array}$ & $\begin{array}{l}\text { System quality, trust, and } \\
\text { satisfaction }\end{array}$ \\
\hline [5] & ECM & $\begin{array}{l}\text { Social influence, privacy, } \\
\text { mobility, privacy protection, } \\
\text { mobility, usefulness and } \\
\text { satisfaction }\end{array}$ \\
\hline [13] & $\begin{array}{l}\text { Elaboration } \\
\text { Likelihood } \\
\text { Model }\end{array}$ & $\begin{array}{l}\text { Source credibility, perceived } \\
\text { usefulness, perceived } \\
\text { integration, trust, } \\
\text { competitors' marketing } \\
\text { efforts, and subjective norm }\end{array}$ \\
\hline [14] & $\begin{array}{l}\text { Innovation } \\
\text { Diffusion } \\
\text { Theory }\end{array}$ & $\begin{array}{l}\text { Mobility, customization, } \\
\text { security, reputation, trust and } \\
\text { perceived risk }\end{array}$ \\
\hline [10] & $\begin{array}{l}\text { UTAUT; } \\
\text { TAM; DOI }\end{array}$ & $\begin{array}{l}\text { Convenience, social value, } \\
\text { perceived trust, satisfaction, } \\
\text { service quality, effort } \\
\text { expectancy and perceived } \\
\text { risk }\end{array}$ \\
\hline [15] & UTAUT2 & $\begin{array}{l}\text { Performance expectancy, } \\
\text { effort expectancy, social } \\
\text { influence, facilitating } \\
\text { conditions, hedonic } \\
\text { motivation, price value, habit } \\
\text { and perceived risk }\end{array}$ \\
\hline [16] & UTAUT & $\begin{array}{l}\text { Performance expectancy, } \\
\text { effort expectancy, social } \\
\text { influence, perceived } \\
\text { compatibility, customer } \\
\text { involvement, epistemic value, } \\
\text { competitive value, trust and } \\
\text { satisfaction }\end{array}$ \\
\hline
\end{tabular}

\subsection{Unified Theory of Acceptance and Use of} Technology (UTAUT)

The UTAUT is an extension of TAM model and incorporated by four fundamental determinants: performance expectancy, effort expectancy, social influences, and facilitating conditions [17]. Thereinto, performance expectation, effort expectation and social influence has the most significant effect on M-payment adoption [10], Moreover, UTAUT can be extended with additional variables to investigate mobile technology adoption [9]. Moreover, UTAUT has been integrated with other models to evaluate users' behavioral intention [2][10]. In addition, UTAUT also has been implemented to analyze users' continuance intention of using technology [10]. Such as, UTAUT model integrates with perceived trust, satisfaction to evaluate customers' continuance intention of using M-commerce [16].

\subsection{Expectancy Confirmation Model (ECM)}

Expectancy Confirmation Model (ECM) is rooted from the expectation-confirmation theory [18], to explain users' satisfaction and continuance behavior of information system by 3 dimensions, performance expectancy, confirmation and satisfaction [8]. ECM been widely applied with additional variables to explain users' continuance intention of using mobile technology, such as, ECM has been modified with trust and proved that satisfaction and trust significantly affecting continuance intention of mobile shopping [19]. Meanwhile, ECM also has been integrated with other adoption models to investigate IS continuance intention [20]. Such as, combining ECM with TAM for investigating mobile technology continuation [21][22]. In addition, ECM also can be combined with espoused cultural value to analyze the factors affecting continuance intention of $\mathrm{M}$ payment [5].

\subsection{Hofstede's cultural values}

Hofstede defines culture as "the collective programming of the mind which distinguishes the members of one human group from another" [23]. Culture values embody the degree to which people embrace their trusts, values and behaviors of their national culture [24]. Moreover, cultural values have been applied as moderators into various adoption models for investigating behavioral intention of technology acceptance [25]. Such as, Baptista and Oliveira (2015) combined cultural moderators with UTAUT2 and found collectivism, uncertainty avoidance, short term and power distance have significant moderating effects on mobile banking adoption [26]; Aparicio,et al. (2016) integrated TAM and IS success model with Individualism/collectivism moderator to investigate e-learning system adoption [24]; Tam and Oliveira (2019) integrated cultural moderators with TTF model to explain users' performance of mobile banking [27]. Furthermore, cultural moderators also have been applied in adoption models to explain users' continuance intention of mobile technologies [5][15].

\section{PROPOSED HYPOTHESES AND RESEARCH MODEL \\ 3.1 Revisiting UTAUT and ECM}

\subsubsection{Performance expectancy (PE)}

Performance expectancy (PE) is defined as the degree to which the users believe that using a particular technology will facilitate their performance in a certain activity [17]. PE as an important factor significantly determines user's continuance intention, the higher utility users perceived from using M-payment system, the greater continuance usage intention [15][20]. Moreover, PE also has been validated have significant effect on satisfaction towards continuance usage intention of mobile technologies [27], like, mobile banking [20][28]; mobile commerce [16]. Therefore, the following hypotheses are proposed:

H1: Performance expectancy (PE) positively affects continuance intention (CI) of using M-payment.

H2: Performance expectancy (PE) positively affects satisfaction (SA) towards continuously using M-payment.

\subsubsection{Effort expectancy (EE)}

Effort expectancy is defined as the degree of ease associated with users' utilization of a certain technology [17]. Which means perceived ease associated with using mobile technology leading users' higher intention to continuous use it [7][16]. However, some studies found EE has no significant effect on continuance intention towards mobile technology, such as, mobile banking [20] 
and mobile shopping applications [15]. Furthermore, EE is a significant predictor affecting performance expectancy and satisfaction on technology continuance usage [29]. Similar results have been confirmed on mobile technology, like, mobile banking [20], mobile commerce [16] and mobile shopping [21]. Therefore, this study proposes following hypotheses:

H3: Effort expectancy (EE) positively affects continuance intention (CI) of using M-payment.

H4: Effort expectancy (EE) positively affects Performance expectancy (PE) towards continuously using M-payment.

H5: Effort expectancy (EE) positively affects satisfaction (SA) towards continuously using M-payment.

\subsubsection{Social Influence (SI)}

Social influence (SI) is defined as the degree that users perceive from others (e.g. families, friends and colleagues) encourage they should use a certain technology [17]. SI has a significant positive impact on continuance intention to use mobile technologies [13], such as mobile shopping apps [15]. Moreover, SI also affects satisfaction towards mobile technology continuance intention [16] Likewise, SI has been confirmed that has both significant effect on users' satisfaction and continuance usage intention of mobile technology [30]. Therefore, following hypotheses are proposed:

H6: Social influence (SI) positively affects continuance intention (CI) of using M-payment.

H7: Social influence (SI) positively affects satisfaction (SA) towards continuously using M-payment.

\subsubsection{Trust (TR)}

Trust (TR) is originated from social psychology, as a state of individual perceived uncertain vulnerability from others, subsequently conceptualized as a faith regarding the intentions and prospective actions will follow the appropriate behavior of integrity and ability [31]. Specifically, the higher trustworthy users perceived from M-payment system, the higher continuance intention towards using it [11][14]. Trust is positively associated with continuance usage of M-purchase [32]. Furthermore, trust also strongly relates to construct of satisfaction [33]. Perceived trust has been demonstrated that significantly influences satisfaction on continuance usage of M-payment [12], as well as mobile banking [34], mobile websites [35], mobile commerce [36]. Accordingly, this study formulates following hypotheses:

H8: Trust (TR) positively affects continuance intention (CI) of using M-payment.

H9: Trust (TR) positively affects satisfaction (SA) towards continuously using M-payment.

\subsubsection{Confirmation (COF)}

Confirmation (COF) is defined as the degree of users' perception of information system is congruent with their prior expectation and actual performance [8]. This study defines the confirmation is the degree of users' confirmation of their initial expectation for M-payment system. Confirmation is an important predictor determining performance expectancy and satisfaction [8]. Specifically, these results been verified by previous studies related to continuance usage intention of various technologies, such as, web-based services [37], mobile banking [20], and mobile learning system [22]. Therefore, the following hypotheses are proposed:

H10: Confirmation (COF) positively affects satisfaction (SA) towards continuously using M-payment.
H11: Confirmation (COF) positively affects Performance expectancy (PE) towards continuously using M-payment.

\subsubsection{Satisfaction (SA)}

Satisfaction (SA) is defined as cumulative feelings when individual prior emotion is coupled with surrounding disconfirmed expectations [18]. If perceived service performance exceeded the users' expectations, the user will be satisfied, which leading the positive actions towards continuance usage of $\mathrm{M}$ payment [12]. Moreover, previous studies have supported that satisfaction as a significant antecedent affecting users continuance intention towards various mobile technologies, such as mobile banking [20][28], mobile apps [30], mobile commerce [16], and mobile purchases [32]. Therefore, the hypothesis is proposed as followed:

H12: Satisfaction (SA) positively affects continuance intention (CI) of using M-payment

\subsection{Espoused cultural values}

\subsubsection{Long/short-term orientation (LTO)}

Long/short-term orientation (LTO) deals with change from past to future based on its culture traditions [4]. Specifically, a society with high LTO culture value focuses more on the traditions, which emphasizing persistence, relationships, thrift loyalty and trustworthiness [38]. Consequently, once a technology is socially accepted, the speed of change is extremely fast with high LTO culture value by its trustworthiness and commitments features [39]. By this logic, people with high LTO value have stronger beliefs to take risk during uncertainty towards enhancing trust to continuously use M-payment. Accordingly, trust has higher effect on behavioral intention for users with higher values of LTO [38]. Thus, the hypothesis is proposed as followed:

H13: The positive effect of trust (TR) on continuance intention (CI) towards M-payment will be stronger for users with high long/short-term orientation (LTO) value.

\subsubsection{Individualism/ collectivism (IC)}

Individualism/collectivism refers to people's independent preference is conceived as separate from society and identity (individualism), as opposed to where people expect being interdependent as members of group in society to protect themselves in exchange for their loyalty (collectivism) [23]. Moreover, from social psychology perspective, people from collectivistic culture displays higher conformity level and lower initiative level than people from individualistic culture [4][40]. By this logic, people who espouse collectivistic cultural values are more concerned about the opinions of their referent group [25]. Therefore, people from collectivistic culture more readily perceive others' opinions to formulate their behavior and decisions [40][41]. Previous studies validated social influence has more influence on behavioral intention with collectivist culture [42]. On the other hand, people espoused individualism is less affected by others' opinion and focus more on efficiency, speed and performance [4][25]. Effort expectancy of users with high Individualism significantly determines continuance intention of mobile technologies, such as mobile shopping applications [15], mobile commerce [43]. Therefore, this paper proposes following hypotheses:

H14: The positive effect of social influence (SI) on continuance intention (CI) towards M-payment will be stronger for users with high espoused collectivism. 
H15: The positive effect of effort expectancy (EE) on continuance intention (CI) towards M-payment will be stronger for users with high espoused individualism.

\subsubsection{Masculinity/femininity (MF)}

Masculinity/femininity is a measure of psychological gender which people espouses masculine value emphasizing earnings, advancement, competitiveness and performance, as opposed to people espouses feminine value who emphasizes personal goals, like, atmosphere, comfortable work environment, quality of life, and warm personal relationships [4] [25]. Specifically, performance expectancy is closely related to achievement, which users with higher degree of masculinity, performance expectancy will have higher effect on IT adoption [25]. Thus, masculinity has moderate effect between performance expectancy and users' intention to use e-commerce [38]. On the other hand, people who espouses feminine culture values has greater desire for social interaction and more readily to conform to others' suggestion which reflects higher influenceability with social effect [4] [41]. Moreover, femininity value orientation been proved having positive interaction between social influence and technology acceptance [25]. Thus, behaviors of users who espouse feminine culture stronger affected by social influence [44]. Therefore, related hypotheses are proposed as followed:

H16: The positive effect of performance expectancy (PE) on continuance intention (CI) towards M-payment will be stronger for users with high espoused masculinity value.

H17: The positive effect of social influence (SI) on continuance intention (CI) towards M-payment will be stronger for users with high espoused femininity value.

\subsubsection{Power distance (PD)}

Power distance (PD) refers to the degree to which unequal distribution of status is accepted and expected as normal in a given culture [4]. It conditions the extent to which Individuals espoused high power distance value accept and conform the ideas or suggestions from their superiors [4] [25]. Due to this compliance effect, social influence is stronger determining continuance intention of M-payment usage with higher espoused power distance values. similar result supported from technology acceptance [25] and adoption of knowledge management systems [42]. Therefore, the suggested hypothesis is shown in followed:

H18: The positive effect of social influence (SI) on continuance intention (CI) towards M-payment will be stronger for users with high power distance value.

\subsubsection{Uncertainty avoidance (UA)}

Uncertainty avoidance (UA) refers to the users' uncertainty and ambiguity from society's tolerance, that is, people with higher uncertainty avoidance feel threatened by unpredictable and unknown situations, and require predictability through formal rules and supports [4]. Social environment is a valuable determinant to reduce uncertainty by appropriate peer influence of personal experiences and perceptions [25]. By this logic, social influence should be a stronger predictor of behavioral intention of continuance usage of M-payment for individuals with high uncertainty avoidance values. Thus, social influence is strongly affected by the espoused uncertainty avoidance on M-payment continuance usage [5]. This paper proposes followed hypothesis:

H19: The positive effect of social influence (SI) on continuance intention (CI) towards M-payment will be stronger for users with high Uncertainty avoidance (UA) value.

\subsection{Proposed research model}

Based on the above hypotheses, all measurement items are modified to correspond with research purposes and present in Table 2 with relevant references. Moreover, proposed model integrating UTAUT and ECM with Hofstede's cultural values as moderators shows in Figure 1.

Table 2. Measurement constructs, items and references

\begin{tabular}{|c|c|c|}
\hline \begin{tabular}{|l|} 
Constructs \\
\end{tabular} & Items & References \\
\hline $\begin{array}{l}\text { Performance } \\
\text { expectancy } \\
(\mathrm{PE})\end{array}$ & $\begin{array}{l}\text { PE1-I feel M-payment is a useful way of } \\
\text { purchasing. } \\
\text { PE2-Using M-payment makes the handling of } \\
\text { payments easier. } \\
\text { PE3-Using M-payment improves my payment } \\
\text { efficiency } \\
\text { PE4-Using M-payment improves my payment more } \\
\text { quickly. }\end{array}$ & [7] \\
\hline \begin{tabular}{|l} 
Effort \\
expectancy \\
$(\mathrm{EE})$
\end{tabular} & $\begin{array}{l}\text { EE1-Learning how to use M-payment is easy. } \\
\text { EE2-It is easy to follow all the steps of M-payment. } \\
\text { EE3-It is easy to become skillful at using M- } \\
\text { payment. } \\
\text { EE4-Interaction with M-payment is clear and } \\
\text { comprehensible. }\end{array}$ & [7] \\
\hline \begin{tabular}{|l|} 
Social \\
influence (SI)
\end{tabular} & $\begin{array}{l}\text { SI1-People who are important to me (e.g., family } \\
\text { members, close friends, and colleagues) } \\
\text { recommend me using M-payment. } \\
\text { SI2-People who are important to me view the M- } \\
\text { payment as beneficial. } \\
\text { SI3-People who are important to me think it is a } \\
\text { good idea to use M-payments. } \\
\text { SI4-People who are important to me support me to } \\
\text { use of M-payment. }\end{array}$ & [3] \\
\hline Trust (TR) & $\begin{array}{l}\text { TR1-I believe M-payment platforms are competent } \\
\text { and effective in handling my contactless } \\
\text { transactions. } \\
\text { TR2-I believe M-payment platforms keep } \\
\text { customers' interests in mind. } \\
\text { TR3-I believe M-payment platforms are } \\
\text { trustworthy. } \\
\text { TR4-I believe M-payment platform implement } \\
\text { adequate security measures to secure the } \\
\text { transactions for users. } \\
\text { TR5-I believe that legal frameworks for M- } \\
\text { payment provision are sufficiently robust to protect } \\
\text { consumers. }\end{array}$ & {$[14]$} \\
\hline $\begin{array}{l}\text { Confirmation } \\
(\mathrm{COF})\end{array}$ & $\begin{array}{l}\text { COF-1 My experience with using M-banking was } \\
\text { better than what I expected } \\
\text { COF-2 The service level provided by M-banking } \\
\text { was better than what I expected } \\
\text { COF-3The benefits provided by M-banking was } \\
\text { better than what I expected }\end{array}$ & [8] \\
\hline $\begin{array}{l}\text { Satisfaction } \\
\text { (SA) }\end{array}$ & $\begin{array}{l}\text { SA1- I was very satisfied that M-payment meets } \\
\text { my requirements } \\
\text { SA2-I am satisfied with M-payment efficiency } \\
\text { SA3- My interaction with the m-payments system } \\
\text { was very satisfying } \\
\text { SA4-I have a positive attitude toward using M- } \\
\text { payments for purchasing. }\end{array}$ & [45] \\
\hline $\begin{array}{l}\text { Long/short- } \\
\text { term } \\
\text { orientation } \\
\text { (LTO) }\end{array}$ & $\begin{array}{l}\text { LTO1-Respect for tradition is important for me. } \\
\text { LTO2- Personal steadiness and stability is } \\
\text { important to me. } \\
\text { LTO3- I work hard for success in the future } \\
\text { LTO4-I have a long-term planning for performing } \\
\text { a particular task }\end{array}$ & [6] \\
\hline $\begin{array}{l}\text { Individualism } \\
\text { collectivism } \\
\text { (IC) }\end{array}$ & $\begin{array}{l}\text { IC1- Being accepted as a member of a group is } \\
\text { more important than having autonomy and } \\
\text { independence. } \\
\text { IC2- Group success is more important than } \\
\text { individual success. } \\
\text { IC3- Group welfare is more important than } \\
\text { individual rewards. } \\
\text { IC4- Being loyal to a group is more important than }\end{array}$ & [6] \\
\hline
\end{tabular}




\begin{tabular}{|c|c|c|}
\hline & individual gain. & \\
\hline $\begin{array}{l}\text { Masculinity/f } \\
\text { emininity } \\
\text { (MF) }\end{array}$ & $\begin{array}{l}\text { MF1-It is more important for men to have a } \\
\text { professional career than it is for women to have one } \\
\text { MF2- It is preferable that male has a high-level } \\
\text { position than a female. } \\
\text { MF3-There are some jobs that a man can always do } \\
\text { better than a woman. } \\
\text { MF4-Men usually solve problems with logical } \\
\text { analysis; women usually solve problems with } \\
\text { intuition. } \\
\text { MF5- Males are more focusing on achievement and } \\
\text { success and females are more focusing on } \\
\text { relationships and quality of life. }\end{array}$ & 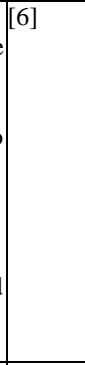 \\
\hline $\begin{array}{l}\text { Power } \\
\text { distance (PD) }\end{array}$ & \begin{tabular}{|l|} 
PD1- People in higher positions should make most \\
decisions without consulting people in lower \\
positions. \\
PD2- People in higher positions should not ask the \\
opinions of people in lower positions too \\
frequently. \\
PD3- People in higher positions should avoid social \\
interaction with people in lower positions. \\
PD4-People in higher positions should not delegate \\
important tasks to people in lower positions \\
PD5- People in lower positions should not disagree \\
with decisions by people in higher positions. \\
\end{tabular} & [6] \\
\hline $\begin{array}{l}\text { Uncertainty } \\
\text { avoidance } \\
\text { (UA) }\end{array}$ & $\begin{array}{l}\text { UA1- I do not use M-payment content when I am } \\
\text { unsure of its quality. } \\
\text { UA2- Specific rules and regulations are important } \\
\text { to me } \\
\text { UA3- It is important to have instructions spelled } \\
\text { out in detail so that I always know what I'm } \\
\text { expected to do. } \\
\text { UA4- It is important to closely follow instructions } \\
\text { and procedures to use M-payment. }\end{array}$ & {$[6][27]$} \\
\hline $\begin{array}{l}\text { Continuance } \\
\text { intention (CI) }\end{array}$ & $\begin{array}{l}\text { CI1-Given the opportunity, I will use M-payment. } \\
\text { CI2-I am willing to use M-payment in the near } \\
\text { future. } \\
\text { CI3-I am open to using M-payment in the near } \\
\text { future. }\end{array}$ & [7] \\
\hline
\end{tabular}

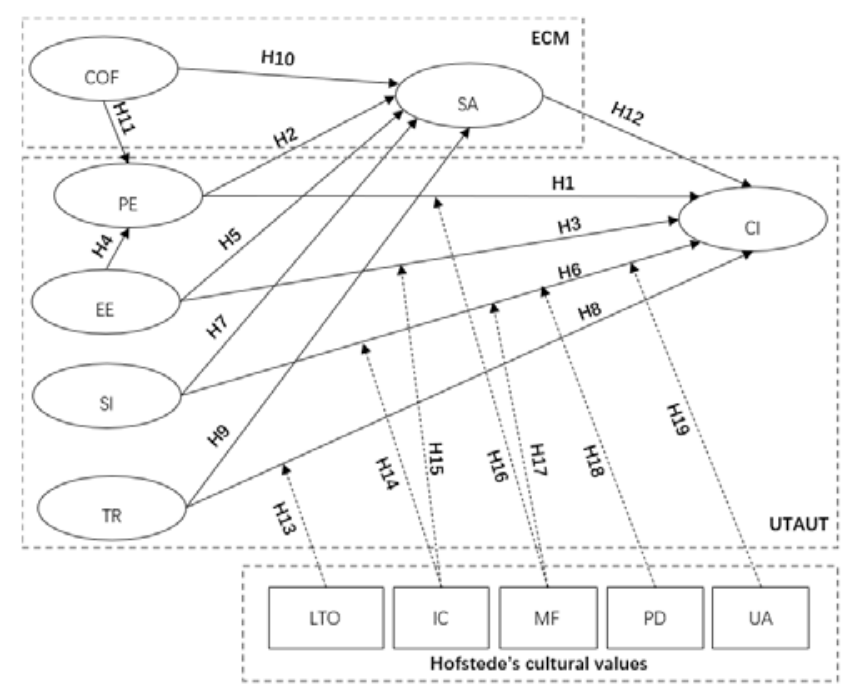

(PE=Performance expectancy, $\mathbf{E E}=E$ Effort expectancy, $\mathbf{S I}=$ Social influence, $\mathbf{T R}=$ Trust, $\mathbf{C O F}=$ Confirmation, $\mathrm{SA}=$ Satisfaction; $\mathrm{Cl}=$ Continuance intention; LOT=Long/short-term orientation:

IC=Individualism/collectivism; $\mathbf{M F}=$ Masculinity/femininity; $\mathbf{P D}=$ Power distance; $U A=$ Uncertainty avoidance)

Figure 1. Research model with proposed hypotheses relations

\section{FUTURE RESEARCH}

The future research of this study will consist data collection, data analysis and discussion sections to explain factors influencing user's continuance intention to use M-payment.
Online questionnaire survey will be applied for data collection. Specifically, the questionnaire will consist of two parts. The first part contains the respondents' demographic data with close-ended questions, including gender, age, education, occupation and $\mathrm{M}$ payment experience. The second part is developed by implementing constructs and items from previous hypotheses and measured by five-point Likert scale (from strongly disagree = " 1 " to strongly agree $=$ “ 5 "), which consisting of 49 measurement items as indicators to explain perceived benefits, performance expectancy, effort expectancy, social influence, trust, individualism/collectivism, masculinity/femininity, power distance, uncertainty avoidance long/short-term orientation and continuance intention. Afterwards, after removing the data with missing values, the valid data will be evaluated by KolmogorovSmirnov (K-S) test for non-response bias [46], and Harman's onefactor test for common method bias [47].

Furthermore, Partial Least Squares Structural Equation Model (PLS-SEM) will be applied by SmartPLS through the two-step approach to validate measurement model and structural model [48]. Measurement model will be assessed by construct reliability (composite reliability $>0.7$; Cronbach's alpha $>0.7$ ), indicator reliability (indicator loading $>0.7$ ), convergent validity (Average variance extracted $>0.5$ ), and discriminant validity (FornellLarcker criteria, cross-loadings criteria and heterotrait-monotrait) to verify the fitness between indicators and latent variables. Moreover, the model-fit will be assessed by Standard root meansquare residual (SRMR) and Normed fit index (NFI). In addition, structural model will be examined by PLS estimation results, including $\mathrm{R}^{2}$ of endogenous variables and path coefficients of internal structure, to assess explanatory power of structural model and test the hypotheses. Accordingly, discussion section will be based on the results of data analysis to evaluate the factors affecting users' continuance intention of using M-payment under culture moderate effect and provide relevant theorical and practical contributions.

\section{CONCLUSION}

This study proposes a comprehensive model integrating UTAUT and ECM with trust to explain Chinese users' continuance intention of using M-payment under culture moderate effect. Moreover, the proposed model fills the gap of traditional adoption models only focusing on users' technological perception and limited studies on continuance intention of using technology under cultural moderation. Meanwhile, this study also provides an overview of the future study to assess proposed model. In addition, the proposed model and measurement in this study can be used as reference for relevant studies.

\section{REFERENCES}

[1] Worldpay. 2020. Global Payments Reports. Available at: https://worldpay.globalpaymentsreport.com/ (Accessed: 02 June 2020)

[2] Di Pietro, L., Guglielmetti Mugion, R., Mattia, G., Renzi, M. F. and Toni, M. 2015. The Integrated Model on Mobile Payment Acceptance (IMMPA), An empirical application to public transport. Transportation Research Part C: Emerging Technologies. Elsevier Ltd, 56, 463-479. doi: 10.1016/j.trc.2015.05.001.

[3] Cao, Q. and Niu, X. 2019. Integrating context-awareness and UTAUT to explain Alipay user adoption. International Journal of Industrial Ergonomics. Elsevier, 69(March 2018), 9-13. 
[4] Hofstede, G. 1984. Culture’s Consequences. Newbury Park, CA: Sage.

[5] Lu, J. Wei, J., Yu, C. and Liu, C. 2017. How do post-usage factors and espoused cultural values impact mobile payment continuation?. Behaviour and Information Technology. Taylor \& Francis, 36(2), 140-164.

[6] Cruz-Cárdenas, J., Zabelina, E., Deyneka, O. and GuadalupeLanas, J. 2019. Role of demographic factors, attitudes toward technology, and cultural values in the prediction of technology-based consumer behaviors: A study in developing and emerging countries. Technological Forecasting and Social Change. Elsevier, 149(October).

[7] Venkatesh, V., Thong, J. Y., Chan, F. K., H. Hu, P. J. and Brown, S. A. 2011. Extending the Two-Stage Information Systems Continuance Model: Incorporating UTAUT Predictors and the Role of Context. Information Systems Journal, 21(6), 527-555.

[8] Bhattacherjee, A. 2001. Understanding information systems continuance: An expectation-confirmation model. MIS Quarterly, 25(3), 351-370.

[9] Kaitawarn, C. 2015. Factor Influencing the Acceptance and Use of M-Payment in Thailand: A Case Study of AIS mPAY Rabbit. Review of Integrative Business \& Economics Research, 4(3), 222-230.

[10] Liébana-Cabanillas, F., Molinillo, S. and Ruiz-Montañez, M. 2018. To use or not to use, that is the question: Analysis of the determining factors for using NFC mobile payment systems in public transportation. Technological Forecasting and Social Change. Elsevier, 139(March 2018), 266-276.

[11] Zhou, T. 2013. An empirical examination of continuance intention of mobile payment services. Decision Support Systems. Elsevier B.V., 54(2), 1085-1091.

[12] Dlodlo, N. 2014. The relationships among service quality, Trust, User satisfaction and post-adoption intentions in Mpayment services. Mediterranean Journal of Social Sciences, 5(23), 165-175.

[13] Zhu, D. H., Lan, L. Y. and Chang, Y. P. 2017. Understanding the Intention to Continue Use of a Mobile Payment Provider: An Examination of Alipay Wallet in China. International Journal of Business and Information, 12(4), 369-390.

[14] Shao, Z. Zhang, L., Li, X., and Guo, Y. 2018. Antecedents of Trust and Continuance Intention in Mobile Payment Platforms: The Moderating Effect of Gender. Electronic Commerce Research and Applications. Elsevier, 33(December 2018), p. 100823.

[15] Chopdar, P. K. and Sivakumar, V. J. 2019. Understanding continuance usage of mobile shopping applications in India: the role of espoused cultural values and perceived risk. Behaviour and Information Technology. Taylor \& Francis, 38(1), 42-64.

[16] Marinković, V., Đorđević, A. and Kalinić, Z. 2020. The moderating effects of gender on customer satisfaction and continuance intention in mobile commerce: a UTAUT-based perspective. Technology Analysis and Strategic Management. Taylor \& Francis, 32(3), 306-318.

[17] Venkatesh, V. Morris, M. G., Davis, G. B. and Davis, F. D. 2003. User acceptance of information technology: Toward a unified view. MIS Quarterly, 27(3), 425-478.
[18] Oliver, R. 1980. A cognitive model of the antecedents and consequences of satisfaction decisions. Journal of Marketing Research, 17(4), 460-469.

[19] Hung, M. C., Yang, S.T. and Hsieh, T. 2012. AN EXAMINATION OF THE DETERMINANTS OF MOBILE SHOPPING CONTINUANCE. International Journal of Electronic Business Management, 10(1), 29-37.

[20] Yuan, S. Liu, Y., Yao, R. and Liu, J. 2016. An investigation of users' continuance intention towards mobile banking in China. Information Development, 32(1), 20-34.

[21] Shang, D. and Wu, W. 2017. Understanding Mobile Shopping Consumers' Continuance Intention. Industrial Management \& Data Systems, 117 (1), 213-227.

[22] Alshurideh, M., Al Kurdi, B. and Salloum, S. A. 2020. Examining the Main Mobile Learning System Drivers' Effects: A Mix Empirical Examination of Both the Expectation-Confirmation Model (ECM) and the Technology Acceptance Model (TAM). Advances in Intelligent Systems and Computing, 1058, 406-417.

[23] Hofstede, G. 1980. Culture's Consequences: International Differences in Work-Related Values. Beverly Hills, CA: Sage.

[24] Aparicio, M., Bacao, F. and Oliveira, T. 2016. Cultural impacts on e-learning systems' success. Internet and Higher Education. Elsevier Inc., 31(June, 2016), 58-70.

[25] Srite, M. and Karahanna, E. 2006. The role of espoused national cultural values in technology acceptance. MIS Quarterly: Management Information Systems, 30(3), 679704.

[26] Baptista, G. and Oliveira, T. 2015. Understanding mobile banking: The unified theory of acceptance and use of technology combined with cultural moderators. Computers in Human Behavior, 50, 418-430.

[27] Tam, C. and Oliveira, T. 2019. Does culture influence mbanking use and individual performance?. Information and Management. Elsevier, 56(3), 356-363.

[28] Susanto, A., Y. Chang, and Ha, Y. 2016. Determinants of Continuance Intention to Use the Smartphone Banking Services: An Extension to the Expectation-confirmation Model. Industrial Management \& Data Systems, 116(3), 508-525.

[29] Kim, S. S. and Malhotra, N. K. 2005. A longitudinal model of continued IS use: An integrative view of four mechanisms underlying postadoption phenomena. Management Science, 51(5), 741-755.

[30] Hsiao, C.H., Chang, J. J. and Tang, K.Y. 2016. Exploring the Influential Factors in Continuance Usage of Mobile Social Apps: Satisfaction, Habit, and Customer Value Perspectives. Telematics and Informatics, 33, 342-355.

[31] Gefen, D. 2000. E-commerce: The role of familiarity and trust. Omega, 28(6), 725-737.

[32] Gao, L., Waechter, K. A. and Bai, X. 2015. Understanding consumers' continuance intention towards mobile purchase: A theoretical framework and empirical study - A case of China. Computers in Human Behavior. Elsevier Ltd, 53, 249-262.

[33] Sharma, S. K. and Sharma, M. 2019. Examining the role of trust and quality dimensions in the actual usage of mobile banking services: An empirical investigation. International 
Journal of Information Management. Elsevier, 44(July 2018), 65-75.

[34] Liébana-Cabanillas, F., Muñoz-Leiva, F., Sánchez-Fernández, J. and Viedma-Del Jesús, M.I., 2016. The moderating effect of user experience on satisfaction with electronic banking: empirical evidence from the Spanish case. IseB, 14 (1), 141165.

[35] Zhou, T., 2011. Examining the critical success factors of mobile website adoption. Online Inf. Rev. 35(4), 636-652.

[36] Jarvenpaa, S. L., Lang, K.R., Takeda, Y. and Tuunainen, V. K. 2003). Mobile commerce at crossroads. Communications of the ACM, 46(12), 41-44.

[37] Lee, Y. and Kwon, O. (2011) Intimacy, familiarity and continuance intention: An extended expectation-confirmation model in web-based services. Electronic Commerce Research and Applications, 10(3), 342-357.

[38] Yoon, C. 2009. The effects of national culture values on consumer acceptance of e-commerce: Online shoppers in China. Information and Management, 46(5), 294-301. doi: 10.1016/j.im.2009.06.001.

[39] Lee, S. G., Trimi, S. and Kim, C. 2013. The impact of cultural differences on technology adoption. Journal of World Business. Elsevier Inc., 48(1), 20-29.

[40] Bond, R. and P. B. Smith. 1996. Culture and Conformity: A Meta-analysis of Studies Using Asch’s (1952b, 1965) Line Judgment Task. Psychological Bulletin, 119 (1), 113-137.

[41] Roberts, A. R. 1991. Contemporary Perspectives on Crisis Intervention and Prevention. Englewood Cliffs, NJ: Prentice Hall.
[42] Lin, H. C. 2014. An investigation of the effects of cultural differences on physicians' perceptions of information technology acceptance as they relate to knowledge management systems. Computers in Human Behavior, 38(February), 368-380.

[43] Hung, C. L. and Chou, J. C. L. 2014. Examining the Cultural Moderation on the Acceptance of Mobile Commerce. International Journal of Innovation \& Technology Management, 11(2), 1-19.

[44] Manrai, L. A. and Manrai, A. K. 2011. Hofstede’s Cultural Dimensions and Tourist Behaviors: A Review and Conceptual Framework. Journal of Economics, Finance \& Administrative Science, 16(31), 23-48.

[45] Pereira, H. G., Salgueiro, M. F. and Rita, P. 2016. Online purchase determinants of loyalty: The mediating effect of satisfaction in tourism. Journal of Retailing and Consumer Services, 30, 279-291.

[46] Ryans, A. B. 1974. Estimating consumer preferences for a new durable brand in an established product class. Journal of Marketing Research, 11(4), 434-443.

[47] Podsakoff, P. M., MacKenzie, S. B., Lee, J. Y. and Podsakoff, N. P. 2003. Common method biases in behavioral research: A critical review of the literature and recommended remedies. Journal of Applied Psychology, 88(5), 879-903.

[48] Anderson, J.C. and Gerbing, D. W. 1988. Structural equation modeling in practice: A review and recommended two-step approach. Psychological Bull, 103(3), 411-423. 